\title{
A single nucleotide polymorphism in the promoter region (rs10877887) of let-7 is associated with hepatocellular carcinoma in a Chinese population
}

\author{
Z.Y. Sui*, J. Li*, G.L. Cheng and S.F. Wang \\ Department of Gastroenterology, \\ The Second Affiliate Hospital of Soochow University, Suzhou, China \\ These authors contributed equally to this study. \\ Corresponding author: S.F. Wang \\ E-mail: sfwang59@sina.cn
}

Genet. Mol. Res. 15 (2): gmr.15027661

Received September 17, 2015

Accepted January 8, 2016

Published May 13, 2016

DOI http://dx.doi.org/10.4238/gmr.15027661

\begin{abstract}
Hepatocellular carcinoma (HCC) is a complex polygenic disease whose development is dependent on many genetic factors. The let-7 family, an important and widely studied microRNA family, has been shown to play an important role in the initiation and progression of HCC. In this study, we examined the possible associations between single-nucleotide polymorphisms in the promoter region of the let7 family (rs10877887) and the susceptibility and prognosis of HCC, using a case-control research model. Eighty-nine HCC patients and 95 healthy controls were genotypes by direct sequencing, and the correlation between rs 10877887 genotypes and HCC susceptibility was evaluated using an unconditional logistic regression model. Populations with the $\mathrm{CT}+\mathrm{CC}$ genotype were at a significantly higher risk of $\mathrm{HCC}$ compared to those with the TT genotype (CT + CC vs TT: odds ratio $=3.52,95 \%$ confidence interval $=1.90-6.52 ; \mathrm{P}<0.05)$. Furthermore,
\end{abstract}


we discovered that the genetic variant of rs10877887 might serve as a prognostic marker for survival in HCC patients, as the CT + CC genotype was associated with poor prognosis.

Key words: Hepatocellular carcinoma; let-7; Single nucleotide polymorphism

\section{INTRODUCTION}

Hepatocellular carcinoma (HCC) is a type of cancer that is predominantly prevalent among the Chinese population, and is known to widely affect public health (He et al., 2005; Jemal et al., 2011). So far, several studies have identified the important role played by various genetic factors in the progression of HCC (Villanueva et al., 2010; Tang et al., 2012; Marquardt et al., 2013).

MicroRNA (miRNA) are a class of endogenous, small (approximately 22-nucleotide), non-coding, single-stranded RNA that regulate the gene expression and affect gene function. An increasing number of studies have reported that miRNAs were involved in various developmental and physiological processes. Hundreds of miRNA are abnormally expressed in human disease. Thousands of human genes or protein-coding genes function as miRNA targets (Lewis et al., 2005; Xie et al., 2005). let-7 is the first miRNA identified in humans. The hsa-let-7 family contains 13 members (Boyerinas et al., 2010), a majority of which are involved in oncogenesis (Brueckner et al., 2007; Kumar et al., 2008; Xie et al., 2013; Zhan et al., 2013).

Several single nucleotide polymorphisms (SNPs) have been associated with increased risk and prognosis of many diseases (Shastry, 2009). miRNA-related SNPs, particularly those in miRNA genes and target sites, may influence the miRNA expression and function, thereby affecting cancer susceptibility and patient survival time. So far, several polymorphisms in let-7 binding sites have been reported to be involved in tumors. In this study, we demonstrated that a SNP at let-7 rs10877887 is associated with hepatocellular carcinoma in the Chinese population.

\section{MATERIAL AND METHODS}

\section{Study subjects}

Eighty-nine HCC patients admitted to the Second Affiliate Hospital of Soochow University between 2007 and 2014 were randomly selected for this study. All patients were pathologically diagnosed with HCC after operation. Ninety-five healthy subjects who had undergone physical examination at the same hospital were used as controls (Table 1).

Written informed consent was obtained from all subjects. The study protocol was approved by the Ethics Committee of the Second Affiliate Hospital of Soochow University. Formalin fixation and paraffin-embedded tissue samples of the patients and peripheral vein blood from controls were analyzed.

\section{DNA extraction and genotyping}

The Wizard Genomic DNA Purification kit (Promega, Madison, WI, USA) and the Formalin Fixation and Paraffin Embedded Tissue DNA Extraction kit (Sangon Biotech, 
Shanghai, China) were used to extract genomic DNA from peripheral blood and tumor tissues, respectively ( $\mathrm{Lu}$ et al., 2013). The PCR products were sequenced directly using an ABI 3730 sequencer (Applied Biosystems, Foster City, CA, USA). The following primers were used for sequencing: 5'-TGGTGTCTGACTGCGCTTT-3' (forward) and 5'-CCGAGAGCTACGGGGATGA-3' (reverse). The following PCR conditions were used: denaturation at $95^{\circ} \mathrm{C}$ for $5 \mathrm{~min}, 40$ cycles of denaturation at $95^{\circ} \mathrm{C}$ for $30 \mathrm{~s}$, annealing at $60^{\circ} \mathrm{C}$ for $30 \mathrm{~s}$, and extension at $72^{\circ} \mathrm{C}$ for $30 \mathrm{~s}$, and a final extension at $72^{\circ} \mathrm{C}$ for $5 \mathrm{~min}$.

Table 1. Basic characteristics of study subjects.

\begin{tabular}{|c|c|c|c|}
\hline Variable & Patients $(\mathrm{N}=89)$ & Controls $(\mathrm{N}=95)$ & $\mathrm{P}$ value \\
\hline Age (years) (mean \pm SD) & $58.20 \pm 10.20$ & $60.38 \pm 8.85$ & $>0.05$ \\
\hline \multicolumn{4}{|l|}{ Gender [N (\%)] } \\
\hline Male & $59(66.3)$ & $55(57.9)$ & $>0.05$ \\
\hline Female & $30(33.7)$ & $40(42.1)$ & $>0.05$ \\
\hline \multicolumn{4}{|l|}{ Differentiation [N (\%)] } \\
\hline Well & $2(2.3)$ & & \\
\hline Moderate & $51(57.3)$ & & \\
\hline Poor & $36(40.4)$ & & \\
\hline \multicolumn{4}{|l|}{ Serum level of tumor markers } \\
\hline ALT (IU/L) & $56(2-605)$ & & \\
\hline AST (IU/L) & $72(18-711)$ & & \\
\hline Alpha fetoprotein (AFP) (mg/L) & $259.6(1.96-2518)$ & & \\
\hline Total bilirubin $(\mathrm{mg} / \mathrm{dL})$ & $18.5(2.1-308)$ & & \\
\hline HBV-DNA (copies/mL) & $6,384(189-580,000)$ & & \\
\hline \multicolumn{4}{|l|}{ TNM stage } \\
\hline $\mathrm{I}$ & $30(33.8)$ & & \\
\hline II & $52(58.4)$ & & \\
\hline III & $5(5.6)$ & & \\
\hline IV & $2(2.2)$ & & \\
\hline
\end{tabular}

For non-normal distributions, median (P25-P75) was used. SD = standard deviation; HBV = hepatitis B virus; ALT $=$ alanine transaminase; $\mathrm{AST}=$ aspartate aminotransferase.

\section{Statistical analysis}

All statistical analyses were performed with SAS v.17.0 (SAS Institute, Cary, NC, USA). All statistical tests were 2-sided, and the differences were considered to be statistically significant when $\mathrm{P}<0.05$. Furthermore, the adjusted (by age and gender) odds ratios (ORs) and $95 \%$ confidence intervals $(95 \% \mathrm{CI})$ of a non-conditional logistic regression model were also used to estimate the association between rs 10877887 genotypes and susceptibility to HCC.

\section{RESULTS}

\section{Case characteristics}

One hundred and eighty-four samples (89 patients and 95 controls) were included in this study. The characteristics of all cases are summarized in Table 1. The case and control groups were age- and gender-matched $(\mathrm{P}>0.05)$. Thirty $(33.8 \%)$ of the 89 HCC patients were classified as TNM stage I, and $52(58.4 \%)$ were in TNM stage II. Fifty-one (57.3\%) patients showed moderate differentiation, while $36(40.4 \%)$ displayed low differentiation. The samples obtained from the remaining patients $(2.3 \%)$ were well differentiated. Further analyses indicated that patients at an advanced TNM stage showed poor prognosis (data not shown). 


\section{Genotyping and association analysis}

Direct sequencing allowed the genotyping of SNP rs10877887 in all samples. All samples were analyzed for conformance with the Hardy-Weinberg equilibrium $(\mathrm{P}=0.305$ and 0.482 , respectively), and all data was further analyzed.

Twenty-five HCC patients $(25 / 89 ; 28.1 \%)$ were TT homozygotes, while the remaining 64 (71.9\%) were CT or CC heterozygotes (Table 2). The frequency of the TT and CT $+\mathrm{CC}$ genotypes in control subjects were 57.9 and $42.1 \%$, respectively. After adjusting for age and gender by logistic regression analysis, we discovered that the different genotypes played a significant role in determining susceptibility to $\mathrm{HCC}(\mathrm{CT}+\mathrm{CC} v s \mathrm{TT}$ : $\mathrm{OR}=3.52,95 \% \mathrm{CI}=1.90-6.52 ; \mathrm{P}<0.01)$.

Table 2. Genotype distribution in cases and controls.
\begin{tabular}{|l|c|c|c|c}
\hline Variables & $\begin{array}{c}\text { Cases }(\mathrm{N}=89) \\
\mathrm{N}(\%)\end{array}$ & $\begin{array}{c}\text { Controls }(\mathrm{N}=95) \\
\mathrm{N}(\%)\end{array}$ & Odds ratio $(95 \% \mathrm{CI})$ & P value \\
\hline Genotypes & & & & \multirow{2}{*}{$<0.01$} \\
\hline TT & $25(28.1)$ & $55(57.9)$ & 1 (reference) & \\
\hline CT + CC & $64(71.9)$ & $40(42.1)$ & $3.52(1.90-6.52)$ & \\
\hline
\end{tabular}

$\mathrm{CI}=$ confidence interval.

Furthermore, a stepwise Cox proportional hazard analysis model was used to analyze HCC survival. Four variables (chemotherapy or TACE status, age, drinking status, and let-7 rs10877887 SNP) were retained in the regression model; significance levels of 0.050 and 0.051 were assigned for removal of variables. As shown in Table 3, the CT $+\mathrm{CC}$ genotype was associated with poor prognosis of HCC.

Table 3. Stepwise Cox regression analysis of hepatocellular carcinoma (HCC) survival.

\begin{tabular}{l|c|c|c|c|c}
\hline Variables & $\beta$ & SE & HR & $95 \%$ CI & P value \\
\hline Chemotherapy or TACE (yes $v s$ no) & -1.2103 & 0.1325 & 0.33 & $0.25-0.44$ & $<0.05$ \\
\hline Age $(>55 v s \leq 55)$ & -0.5323 & 0.2274 & 0.72 & $0.63-0.89$ & $<0.05$ \\
\hline Drinking status (yes $v s$ no) & 0.3954 & 0.2025 & 1.63 & $1.21-1.89$ & $<0.05$ \\
\hline rs10877887 (TT $v$ CT+CC) & -0.2965 & 0.1303 & 0.68 & $0.52-0.94$ & $<0.05$ \\
\hline
\end{tabular}

$\mathrm{TACE}=$ trans-catheter hepatic arterial chemoembolization; $\mathrm{HR}=$ hazard ratio; $\mathrm{CI}=$ confidence interval; $\beta=$ estimated parameter of the regression model; $\mathrm{SE}=$ standard error of the regression model.

\section{DISCUSSION}

HCC is the fourth most common cause of cancer-related deaths worldwide; China alone accounts for 53\% of all liver cancer-related deaths worldwide (Jemal et al., 2011). Despite the considerable advances in HCC management, including liver transplantation, surgical resection, chemotherapy, and molecular therapy, the prognosis of HCC patients remains poor (An et al., 2014). Recent studies have indicated the role of an increasing number of genes in the molecular mechanism of hepatocarcinogenesis. miRNA, a family of small noncoding RNA, often reported to be up- or down-regulated in tumors, also plays a role in tumorigenesis (Farazi et al., 2011; Han et al., 2013). Whereas miR-9 is up-regulated in several forms of cancer including Hodgkin lymphoma, the miR-34 family members are important tumor-suppressors, with multiple targets in key cancer pathways (Jansson and Lund, 2012). The level of expression of miR-26a is reduced in HCC, in accordance with its function as a repressor of the key cyclins, cyclin D2 and E2 (Kota et al., 2009). 
The let-7 miRNA family, which has been extensively researched, is down-regulated in many forms of cancer, and has also been shown to target prominent oncogenes, including $K R A S, M Y C$, and HMGA2 (Johnson et al., 2005; Jansson and Lund, 2012). Let-7 is also downregulated in non-small cell lung cancer patients (Jansson and Lund, 2012), and is associated with poor prognosis (Yanaihara et al., 2006). Although the effect of let-7 on cancer and its mechanism involves a number of processes, SNPs are believed to play a prominent role in all. Two SNPs identified in the promoter region of let-7 have been associated with hepatocellular carcinoma and lung cancer susceptibility (Shen et al., 2015).

The results of our study indicate an association between an SNP in the promoter region (rs10877887) of let-7 and hepatocellular carcinoma in a Chinese Population. The rs 10877887 region incorporates a $\mathrm{CpG}$ island and $\mathrm{TF}$ binding sites; therefore, the $\mathrm{T}>\mathrm{C}$ mutation may influence the binding of transcription factors, as well as the expression of let-7. Patients carrying the $\mathrm{CC}+\mathrm{CT}$ genotype were found to be more likely to develop HCC than those carrying the TT genotype $(\mathrm{OR}=3.52,95 \% \mathrm{CI}=1.90-6.52 ; \mathrm{P}<0.01)$. Moreover, the genetic variant of rs10877887 may serve as a prognostic marker for survival in HCC patients. The $\mathrm{T} \rightarrow \mathrm{C}$ base change of rs 10877887 in the promoter region of let 7 may be a risk factor for HCC.

In conclusion, we discovered that the CT + CC genotype of the rs10877887 SNP of let-7 is significantly associated with an increased risk, and poor prognosis, of HCC in the Chinese population, consistent with the results of other studies. Further investigations including larger sample sizes are warranted to confirm our results, and to define the potential mechanisms of rs10877887 SNP in let-7 in HCC.

\section{Conflicts of interest}

The authors declare no conflict of interest.

\section{REFERENCES}

An J, Liu J, Liu L, Liu Y, et al. (2014). A genetic variant in primary miR-378 is associated with risk and prognosis of hepatocellular carcinoma in a Chinese population. PLoS One 9: e93707. http://dx.doi.org/10.1371/journal. pone. 0093707

Boyerinas B, Park SM, Hau A, Murmann AE, et al. (2010). The role of let-7 in cell differentiation and cancer. Endocr. Relat. Cancer 17: F19-F36. http://dx.doi.org/10.1677/ERC-09-0184

Brueckner B, Stresemann C, Kuner R, Mund C, et al. (2007). The human let-7a-3 locus contains an epigenetically regulated microRNA gene with oncogenic function. Cancer Res. 67: 1419-1423. http://dx.doi.org/10.1158/00085472.CAN-06-4074

Farazi TA, Spitzer JI, Morozov P and Tuschl T (2011). miRNAs in human cancer. J. Pathol. 223: 102-115. http://dx.doi. org/10.1002/path.2806

Han Y, Pu R, Han X, Zhao J, et al. (2013). Associations of pri-miR-34b/c and pre-miR-196a2 polymorphisms and their multiplicative interactions with hepatitis B virus mutations with hepatocellular carcinoma risk. PLoS One 8: e58564. http://dx.doi.org/10.1371/journal.pone.0058564

He J, Gu D, Wu X, Reynolds K, et al. (2005). Major causes of death among men and women in China. N. Engl. J. Med. 353: 1124-1134. http://dx.doi.org/10.1056/NEJMsa050467

Jansson MD and Lund AH (2012). MicroRNA and cancer. Mol. Oncol. 6: 590-610. http://dx.doi.org/10.1016/j. molonc.2012.09.006

Jemal A, Bray F, Center MM, Ferlay J, et al. (2011). Global cancer statistics. CA Cancer J. Clin. 61: 69-90. http://dx.doi. org/10.3322/caac.20107

Johnson SM, Grosshans H, Shingara J, Byrom M, et al. (2005). RAS is regulated by the let-7 microRNA family. Cell 120: 635-647.http://dx.doi.org/10.1016/j.cell.2005.01.014

Genetics and Molecular Research 15 (2): gmr.15027661

CFUNPEC-RP www.funpecrp.com.br 
Kota J, Chivukula RR, O’Donnell KA, Wentzel EA, et al. (2009). Therapeutic microRNA delivery suppresses tumorigenesis in a murine liver cancer model. Cell 137: 1005-1017. http://dx.doi.org/10.1016/j.cell.2009.04.021

Kumar MS, Erkeland SJ, Pester RE, Chen CY, et al. (2008). Suppression of non-small cell lung tumor development by the let-7 microRNA family. Proc. Natl. Acad. Sci. USA 105: 3903-3908. http://dx.doi.org/10.1073/pnas.0712321105

Lewis BP, Burge CB and Bartel DP (2005). Conserved seed pairing, often flanked by adenosines, indicates that thousands of human genes are microRNA targets. Cell 120: 15-20.http://dx.doi.org/10.1016/j.cell.2004.12.035

Lu Y, Lu J, Liu Q, Niu J, et al. (2013). A c.464T>a mutation in VHL gene in a Chinese family with VHL syndrome. $J$. Neurooncol. 111: 313-318. http://dx.doi.org/10.1007/s11060-012-1015-0

Marquardt JU, Fischer K, Baus K, Kashyap A, et al. (2013). Sirtuin-6-dependent genetic and epigenetic alterations are associated with poor clinical outcome in hepatocellular carcinoma patients. Hepatology 58: 1054-1064.http://dx.doi. org $10.1002 /$ hep. 26413

Shastry BS (2009). SNPs: impact on gene function and phenotype. Methods Mol. Biol. 578: 3-22. http://dx.doi. org/10.1007/978-1-60327-411-1_1

Shen LQ, Xie YZ, Qian XF, Zhuang ZX , et al. (2015). A single nucleotide polymorphism in the promoter region of let-7 family is associated with lung cancer risk in Chinese. Genet. Mol. Res. 14: 4505-4512. http://dx.doi.org/10.4238/2015. May.4.8

Tang J, Guo YS, Zhang Y, Yu XL, et al. (2012). CD147 induces UPR to inhibit apoptosis and chemosensitivity by increasing the transcription of Bip in hepatocellular carcinoma. Cell Death Differ. 19: 1779-1790. http://dx.doi. org/10.1038/cdd.2012.60

Villanueva A, Minguez B, Forner A, Reig M, et al. (2010). Hepatocellular carcinoma: novel molecular approaches for diagnosis, prognosis, and therapy. Annu. Rev. Med. 61: 317-328. http://dx.doi.org/10.1146/annurev. $\underline{\text { med.080608.100623 }}$

Xie K, Liu J, Zhu L, Liu Y, et al. (2013). A potentially functional polymorphism in the promoter region of let-7 family is associated with survival of hepatocellular carcinoma. Cancer Epidemiol. 37: 998-1002. http://dx.doi.org/10.1016/j. canep.2013.09.005

Xie X, Lu J, Kulbokas EJ, Golub TR, et al. (2005). Systematic discovery of regulatory motifs in human promoters and 3' UTRs by comparison of several mammals. Nature 434: 338-345. http://dx.doi.org/10.1038/nature03441

Yanaihara N, Caplen N, Bowman E, Seike M, et al. (2006). Unique microRNA molecular profiles in lung cancer diagnosis and prognosis. Cancer Cell 9: 189-198.http://dx.doi.org/10.1016/j.ccr.2006.01.025

Zhan M, Qu Q, Wang G, Liu YZ, et al. (2013). Let-7c inhibits NSCLC cell proliferation by targeting HOXA1. Asian Pac. J. Cancer Prev. 14: 387-392.http://dx.doi.org/10.7314/APJCP.2013.14.1.387 